\title{
Impact of Crash Characteristics, Safety Accessories on Injury Patterns among Motorcycle Users Attending Teaching Hospital, Karapitiya, Galle
}

\author{
Janaki Warushahennadi ${ }^{1}$, Dhammi Luwishewa ${ }^{2}$, Aravinda Gamage ${ }^{3}$, Vijitha De Silva ${ }^{3}$, \\ H. C. Ambawatte ${ }^{4}$
}

\begin{abstract}
Introduction: Road traffic accidents involving motor cycles often results in severe morbidity and mortality. There has been a significant increase in incidences of motorcycle accidents in Sri Lanka in the recent past. This study was conducted to understand the different factors related to the motor cycles, users and the roads which determine the injury patterns on victims, who were presented to the Teaching Hospital, Karapitiya, Sri Lanka.
\end{abstract}

Methods: This prospective analytical study was carried out among the motor cycle users admitted during the six months from January 2015.

Results: A total of 272 patients (233 males) ranging in age from 6 months to 73 years (mean $=30$ years) were included. Out of all patients 194 (71.3\%) were riders. About 50.7\% of the incidents happened during the daytime. Majority of patients had ridden classical motor cycles (66.2\%) and $56.6 \%$ of all bicycles had a crash bar. About $9.9 \%$ of the victims were wearing full face helmets whereas $11.4 \%$ were without helmets. It is recorded that $51.5 \%$ of the incidents occurred in urban areas and $91.2 \%$ of accidents were on tarred roads. Majority incidences $(82.4 \%)$ happened when it was not raining. Abrasions were the commonest $(69.5 \%)$ injury and $47.1 \%$ of patients had injuries which fell in to Grievous Hurt Category according to the Penal Code of Sri Lanka. Wearing helmets is a protective factor from head injuries $(\mathrm{p}=0.020)$. Full face helmets provided protection from facial injuries than partial coverage helmets $(\mathrm{p}=0.037)$. Conclusions: Motor cycle users sustain different types of injuries and majority was Grievous Hurt category. Wearing helmets is a protective factor from head injuries andfull face helmets provided protection from facial injuries than normal helmets.

Keywords: motorcycle, injuries, accidents

\footnotetext{
1. Department of Forensic Medicine, Faculty of Medicine, Galle, Sri Lanka.

2. Teaching Hospital Karapitya, Galle, Sri Lanka.

3. Department of Community Medicine, Faculty of Medicine, Galle, Sri Lanka.

4. Department of Mechanical \& Manufacturing Engineering, Faculty of Engineering, Galle. Sri Lanka.
} 
WARUSHAHENNADI, J., LUWISHEWA, D., GAMAGE, A.,DE SILVA,V., AMBAWATTE, H.C., Impact of crash characteristics, safety accessories on injury patterns among motorcycle users attending Teaching Hospital, Karapitiya, Galle. Sri Lanka Anatomy Journal (SLAJ), $1(1)$ : 25 -33, 2017.

\section{INTRODUCTION}

Motor cycles are a common mode of transport in Sri Lanka especially among low middle class population due to their affordable price, fast and ease of use and ability to beat traffic jams in urban areas. It constitutes the largest proportion of vehicles which involves in the traffic accidents in Sri Lanka and in recent years there has been a significant increase in mortality and morbidity. According to the Sri Lanka Police traffic statistics 16240 motor cycles involved in traffic accidents in 2010 (1).

According to the World Health Organization report, in 2002 traffic related injuries killed around 1.2 million people and injured more than 50 million others (2). An analysis of motor vehicle crash related deaths indicate that over $40 \%$ of victims are motorized two-wheeled users $(3,4)$. Despite of all these established facts, motor cycle is used as a mean of transportation is on the rise worldwide (5). Many recent reports indicate that motorcycle accident (MCA) victims are young males $(6,7)$ and the head injuries and lower extremity injuries accounted for the major proportion of injuries sustained by motor cycle users $(6,7,8,9)$. The head injuries are attributed to the low use of safety helmets; a situation seen in many developing countries (10). The instability of the motorized two wheeled vehicle, the attitudes of the riders and the factors related to the poor conditions of the roads are the major causes for traffic accidents. The injury patterns depends on the speed of the vehicle, crash characteristics, usage of safety measurements mainly helmets, type of post-crash event etc. It is a universally accepted fact that the usage of helmets protects against head injuries, but it has been argued that motorcycle helmet use decreases rider vision and increases neck injuries (11).

This descriptive cross sectional study was carried out to determine crash characteristics, environmental factors injury patterns and impact of safety measures on the severity of injuries among motorcycle users (MCUs) attending the Teaching Hospital, Karapitiya, Galle.

\section{OBJECTIVES}

The general objective of this study was to understand the different factors related to the motor cycle, road and the rider which determines the injury patterns on motor cycle users in traffic accidents. The specific objectives were to determine the relationship of the injury pattern of motor cycle users with the type of the motor cycle, different

safety mechanisms available in the motor cycle and used by the motor cycle users, 
WARUSHAHENNADI, J., LUWISHEWA, D., GAMAGE, A.,DE SILVA,V., AMBAWATTE, H.C., Impact of crash characteristics, safety accessories on injury patterns among motorcycle users attending Teaching Hospital, Karapitiya, Galle. Sri Lanka Anatomy Journal (SLAJ), $1(1)$ : 25 -33, 2017.

conditions of the road and the crash characteristics.

\section{STUDY DESIGN \& METHODOLOGY}

This descriptive cross-sectional study was carried out at the Teaching Hospital, Karapitiya which is the major tertiary health care institution in the Southern Province of Sri Lanka. The Judicial Medical Officers' (JMOs') Office at the Teaching Hospital, Karapitiya (THK) examines about 10000 patients annually with different medico legal issues such as injuries following traffic accidents, assaults, abuse etc.

The study team analysed 272 MCUs admitted to the Emergency Trauma Centre (ETC) at the THK following traffic accidents during the period of six months from January 2015. All the MCUs who were examined by the authors during the medico legal examination were included in the study. The patients were selected from the history given by the patient and confirmed from the Hospital Police Post records. Each MCU was interviewed and examined after obtaining consent to determine the age, gender, types of injuries, the category of hurt, type of the motor cycle,

crash characteristics, different safety accessories used by the MCU and was available on motor cycles. The type of the injury and the severity of the injuries were determined from the examination findings, considering the radiographic images and after referring the medical records.

\section{DATA ANALYSIS}

Interpretation of the findings was done after careful and complete consideration of all circumstances. Frequencies mean (SD) was employed in the analysis was done using SPSS V.17. Results were considered significant at $\mathrm{p}=0.05$.

\section{ETHICAL CONSIDERATION}

The study was carried out after obtaining the ethical clearance from the Ethical Review Committee, Faculty of Medicine, Galle. The permission was obtained from the Director of the THK to carry out the study on patients in the hospital.

\section{RESULTS}

A total of 272 MCUs were included in the study. Out of the total, 233(85.6\%) were males and 39 were females $(14.4 \%)$. The age of the MCUs were ranging from 6 months to 73 years $($ mean $=30$ years) .The peak incidence was 21-40 years (152 patients, 55.6\%) followed by 0-20 years (65patients, 23.9\%) (Table 01).

Out of the total, $194(71.3 \%)$ were riders. According to the results of this study the number of motor cycle accidents distributed throughout the 24 hours. But the highest number of incidence (58, 
WARUSHAHENNADI, J., LUWISHEWA, D., GAMAGE, A.,DE SILVA,V., AMBAWATTE, H.C., Impact of crash characteristics, safety accessories on injury patterns among motorcycle users attending Teaching Hospital, Karapitiya, Galle. Sri Lanka Anatomy Journal (SLAJ), $1(1)$ : 25 -33, 2017.

$21.3 \%$ ) happened during $0.00-04.00 \mathrm{hrs}$. and the lowest number of incidence (35, $12.9 \%$ ) happened during $20.00-23.00$ hour (Table 02). Almost equal numbers of incidences happened during day time and night time which are 134(49.3\%) and 138(51.7\%) respectively (Fig. 1)

While $51.5 \%$ of the incidents occurred in urban areas the rest occurred in the suburban or rural areas. While 248(91.2\%) accidents were on tarred roads, 10(3.7\%) were on concrete roads (Table 03). Majority incidences (82.4\%) happened when it was not raining. While $157(57.7 \%)$ motor cycles collided with another vehicle, $115(42.3 \%)$ sustained injuries due to various other reasons such as impact with a stationary object, slipping on the road and loss of control or while trying to save a stray dog on the road. The type of motor cycles involved in the accidents were classical motor cycles 180 (66.2\%), scooters 74 (27.2\%), and light mopeds 15 (5.5\%).

When analyzing the different safety accessories available in motor cycles, 154(56.6\%) had crash bars. Different safety accessories used by the MCUs were considered in this study. The safety helmets were categorized into 2 groups. Those were full coverage/face helmets and the partial coverage helmets. Out of the total $241(88.6 \%)$ were wearing safety helmets, Out of which $27(9.9 \%)$ were wearing full face helmets and 214 were wearing partial coverage helmets (Table 5). Out of the total, 207(85.9\%) have fasten the chin strap while the rest $34(14.1 \%)$ either have not fasten or chin straps were absent. Two MCUs were wearing jackets and gloves.

Different injuries were observed on the MCUs considered in the study. Out of the total number of patients, abrasions were present on 189(69.5\%) followed by fracture in $123(45.2 \%)$, lacerations in $109(40.1 \%)$, contusions in $60(22.1 \%)$, cuts in 5(1.8\%), and burns in (20.7\%) respectively. When the distribution of injuries on the body was considered 106(39\%) suffered facial injuries and 46(16.9\%) MCUs had head injuries. There were neck injuries on 10(3.7\%) victims and $2(0.7 \%)$ sustained injuries on genitalia. When the injuries on the extremities were concerned, 147MCUs sustained upper limb injuries and 149 sustained lower limb injuries. Standard statistical tests were used to compare groups and to determine the statistical significance of the association between variables. Wearing helmets were statistically significant protection for a head injuries compared to the MCUs without helmets $(p=0.020)$. Full face helmets provided statistically significant protection from facial injuries than partial coverage helmets $(p=0.037)$.After the 
WARUSHAHENNADI, J., LUWISHEWA, D., GAMAGE, A.,DE SILVA,V., AMBAWATTE, H.C., Impact of crash characteristics, safety accessories on injury patterns among motorcycle users attending Teaching Hospital, Karapitiya, Galle. Sri Lanka Anatomy Journal (SLAJ), $1(1)$ : 25 -33, 2017.

medico legal examination of the patients the injuries were categorized according to the Hurt described in the Penal Code of Sri Lanka. Majority 128(47.1\%) of the victims sustained injuries which amounts to 'Grievous Hurt' (GH) followed by 114(41.9\%) which were 'Non Grievous Hurt'(NGH). Life threatening categories of hurt were observed in $30(11 \%)$ victims (Table 06).

\section{DISCUSSION}

This study was undertaken 272 MCUs who were admitted to the hospital with injuries following traffic accidents. It was observed that the majority of the victims were young males with mean age of 30 years which agrees with similar type of studies done overseas $(6,10,11,12)$. The motorized two-wheeled vehicle is a very unstable and the users are at a risk of sustaining injuries. This study shows that among the users, the riders account for majority injury patterns and agrees with other similar studies $(11,13,14,15)$. This finding suggests that riders constitute the majority among the MCU victims reporting to hospitals.

It is a well-known fact that the incidences of traffic accidents are higher during the peak hours of the day, but this study indicates that the incidence of motor cycle accidents are more or less equal during the 24 hours of the day with highest incidence
$(21.3 \%)$ occurred during early hours of the day. The reasons may be due to the higher speed on empty roads, consumption of alcohol by the rider and the poor lightening systems which we

were unable to asses.

In this study we have observed 2 crash characteristics. One was due to the collision with another vehicle. The other one was accidents on the road due to the reasons such as while trying to avoid a stray dog on the road, due to loss of control or due to the classical "slide and fall" mechanism. This shows how motor cycle users are vulnerable to other vehicles even without impact with other vehicles.

According to the Road Development Authority of Sri Lanka, there are different categories of roads(16). The majority of the MCA occur on the carpeted or tarred roads (Category A, B, C) in urban areas during non-rainy times. Different types of motor cycles are used on roads in Sri Lanka. The classical motor cycles involved in major proportion of MCA and this study indicates that the crash bars which is a safety mechanism available on the motor cycle does not significantly protect the user from sustaining injuries.

A main objective of this study was to identify the impact of using safety helmets in MCA. It seems intuitive that the helmets would protect the user against head injuries but it has been argued that the 
WARUSHAHENNADI, J., LUWISHEWA, D., GAMAGE, A.,DE SILVA,V., AMBAWATTE, H.C., Impact of crash characteristics, safety accessories on injury patterns among motorcycle users attending Teaching Hospital, Karapitiya, Galle. Sri Lanka Anatomy Journal (SLAJ), $1(1)$ : 25 -33, 2017.

using of helmets decrease rider`s vision and increases neck injuries

Beginning from 1985 it is mandatory to wear safety helmets for all motor cycle users in Sri Lanka. Although it is a common knowledge that the helmet usage is low in developing countries average rate of using safety helmets in Sri Lanka is $81 \%(13,15,18)$. The above findings confirm from our study where $88 \%$ were using a safety helmet. Most of the victims who do not use helmets were children. The helmet usage among children is as low as 20\%(18).These findings justify the need for designing a special message for the children who use motor cycles as a mean of transportation to increase their awareness of the dangers of motor cycle use in the absence of protective measures.

Abrasions were the commonest type of injury followed by the fractures which is consistent with other similar studies. Abrasion is the most superficial injury which caused by a blunt force and can sustain during the primary impact of the anatomical area of the victim with the projecting part of the other vehicle or an object or due to the impact with the ground (19). According to the Penal Code of Sri Lanka, majority of the injuries were categorized as either Grievous Hurt or Non Grievous Hurt and there was $11 \%$ of life threatening injuries (20). The face and the extremities were the most vulnerable anatomical areas for injuries. Previous studies have shown that head and the extremity injuries are the commonest causes for morbidity and the mortality in MCA (10). This study indicates that the 55.0\% MCUs had head and facial injuries. Wearing helmets is a protective factor from head injuries $(p=0.020)$. Full face helmets provided protection from facial injuries than partial coverage helmets $(\mathrm{p}=0.037)$.

\section{CONCLUSIONS:}

Young male motor cycle riders constitute the majority among the MCU victims reported to the hospital. This study revealed that the MCAs occur around 24 hours of the day on urban areas. Abrasions and the fractures were the commonest types of the injuries present on the face and extremities. Most of the injuries present on the victims were Grievous Hurt according to the Penal Code of Sri Lanka which implies the severity of the injuries. Therefore it is recommended that the legislative efforts should be taken to promote safety gears used by MCUs and implement necessary rules to reduce the MCAs. 
Table 1. Age groups

\begin{tabular}{ccc}
\hline Age & Frequency & Percentage \\
\hline $0-20$ & 65 & 23.9 \\
$21-40$ & 152 & 55.9 \\
$41-60$ & 47 & 17.3 \\
above 61 & 8 & 2.9 \\
Total & 272 & 100.0 \\
\hline
\end{tabular}

Table 2. Time of incident

\begin{tabular}{ccc}
\hline Time & Frequency & Percentage \\
\hline $0.00-4.00$ & 58 & 21.3 \\
$4.01-8.00$ & 45 & 16.5 \\
$8.01-12.00$ & 44 & 16.2 \\
$12.01-16.00$ & 44 & 16.2 \\
$16.01-20.00$ & 46 & 16.9 \\
$20.01-23.59$ & 35 & 12.9 \\
Total & 272 & 100.0 \\
\hline
\end{tabular}

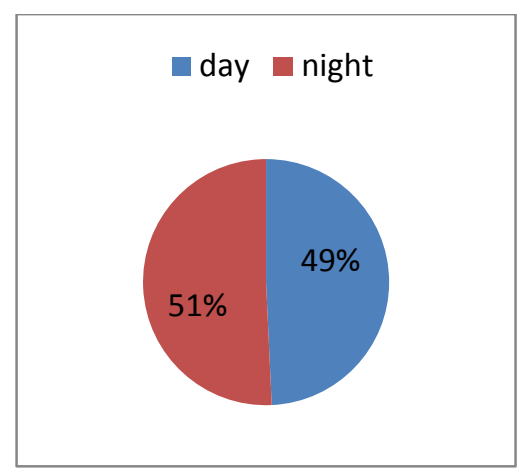

Figure 1. Time of incident
Table 3. Road conditions

\begin{tabular}{rcc}
\hline Road type & Frequency & Percentage \\
\hline Tarred & 248 & 91.2 \\
Concrete & 10 & 3.7 \\
Sand & 3 & 1.1 \\
Mud & 2 & 0.7 \\
Marsh & 3 & 1.1 \\
Gravel & 6 & 2.2 \\
Total & 272 & 100.0 \\
\hline
\end{tabular}

Table 4. Type of motor cycle

\begin{tabular}{ccc}
\hline & Frequency & Percentage \\
\hline Classical & 180 & 66.2 \\
Scooter & 74 & 27.2 \\
$\begin{array}{c}\text { Moped } \\
\text { Other (trail }\end{array}$ & 15 & 5.5 \\
bike etc.) & 3 & 1.1 \\
Total & 272 & 100.0 \\
\hline
\end{tabular}

Table 5. Use of different types of safety helmets

\begin{tabular}{ccc}
\hline & Frequency & Percentage \\
\hline $\begin{array}{c}\text { Full face } \\
\text { Partial } \\
\text { cover } \\
\text { No } \\
\text { helmet }\end{array}$ & 27 & 9.9 \\
Total & 31 & 78.7 \\
\hline
\end{tabular}


Table 6. Category of Hurt

\begin{tabular}{ccc}
\hline & Frequency & Percentage \\
\hline EL & 15 & 5.5 \\
FIOCN & 15 & 5.5 \\
GH & 128 & 47.1 \\
NGH & 114 & 41.9 \\
Total & 272 & 100.0 \\
\hline
\end{tabular}

\section{REFERENCES}

1. Official Web Site of Sri Lanka Police Department. www.police.gov.lk. Web site accessed on 5 March 2017.

2. Peden M, ScurfiEld R, Sleet $D$, et al. World Report on road traffic injury prevention. Geneva: World Health Organization; 2004.

3. Santamariña-Rubio E, Pérez K, Ricart I, Arroyo A, Castellà J, Borrell C. Injury.profiles of road traffic deaths. Accid Anal Prev 2007. Website. Accessed on 10 October 2016.

4. Beck LF, Dellinger AM, O'Neil ME. Motor vehicle crash injury rates by mode of travel, United States: using exposurebased methods to quantify differences. Am J Epidemiol. 2007; Website Accessed on 5 August 2016.

5. Keall MD, Newstead S. Analysis of factors that increase motorcycle rider risk compared to car driver risk. Accid Anal Prev. 2012; Website. Accessed on 10 October 2016.

6. Lateef F. Riding motorcycles: Is it a lower limb hazard? Singapore Med J. 2002.

7. Zargar M, Khaji A, Karbakhsh M. Pattern of motorcycle-related injuries in Tehran, 1999 to 2000: a study in 6 hospitals. East Mediterr Health J. 2006;12(1-2):81

8. Pan Afr Med J. 2014 Nov 17;19:296. doi: 10.11604/pamj.2014.19.296.4885.

Collection 2014.

9. Sisimwo PK., Mwaniki PK., Bii C. Inj Prev. Crash characteristics and injury patterns among commercial motorcycle users attending Kitale level IV District Hospital, Kenya. 2006 Aug; 12(4): 266268. doi: 10.1136/ip.2005.011221.
10. Solagberu BA, Ofoegbu CKP, Nasir AA, Ogundipe UK., Adekanye AO, and Abdur-Rahman LO..Motorcycle injuries in a developing country and the vulnerability of riders, passengers, and pedestrians.BMC Public Health. 2015; 15: 915.Published online 2015 Sep 18. doi: 10.1186/s12889-015-2290-4.

11. Alain C, Julius A, Jean GT, Clovis F and Marcelin N, A prospective pilot cohort analysis of crash characteristics and pattern of injuries in riders and pillion passengers involved in motorcycle crashes in an urban area in Cameroon: lessons for prevention., ochraneDatabaseSyst

Rev. 2008 Jan 23;(1):CD004333.

12. Leijdesdorff HA, Siegerink B, Sier $\mathrm{CF}$, Reurings $\mathrm{MC}$, Schipper IB. Injury pattern, injury severity, and mortality in 33,495 hospital-admitted victims of motorized two-wheeled vehicle crashes in The Netherlands. J Trauma Acute Care Surg 2012; 72:1363-8.

13. Odelowo EOO. Pattern of trauma resulting from motorcycle accidents in Nigerians: a two-year prospective study. Afr J Med Med Sci 1994 23:109-112.

14. Adegbehingbe BO, Oluwadiya KS, Adegbehingbe OO. Motorcycle associated ocular injuries in Ile-Ife, Nigeria. African Journal of Trauma 2004;235-39.

15. Oluwadiya K.S, Oginni IM, Olasinde A A et al, Motorcycle limb injuries in a developing country. West Afr J Med 2004; 23: 42-46.46 Web site accessed on 01.04.2017.

16. Official Website of Road Development Authority.www.rda.gov.lk Web site accessed on $05^{\text {th }}$ March 2017.

17. Liu BC, Ivers R, Norton R, Boufous S, Blows S, Lo SK.. Helmets for 
WARUSHAHENNADI, J., LUWISHEWA, D., GAMAGE, A.,DE SILVA,V., AMBAWATTE, H.C., Impact of crash characteristics, safety accessories on injury patterns among motorcycle users attending Teaching Hospital, Karapitiya, Galle. Sri Lanka Anatomy Journal (SLAJ), $1(1)$ : 25 -33, 2017.

preventing injury in motorcycle riders.ochrane Database Syst Rev. 2008 $23 ;:$ CD004333. doi: 10.1002/14651858.CD004333.

18. Ranaweera PSPA, Department of Civil Engineering, University of Moratuwa.
Electronic Thesis and Dissertation 2014. Web site accessed on 04.04.2017.

19. Pekka S, Knight B, Forensic Pathology $3^{\text {nd }}$ Edition. Arnold Lond. 2004 Edward Arnold (Publishers) Ltd. Pp. 136 - 143.

20. Penal Code of Sri Lanka. Government of Ceylon Legislative Enactments 1970.

\section{CORRESPONDENCE:}

Dr. Janaki Warushahennadi, Department of Forensic Medicine, University of Ruhuna, Sri Lanka.

Email-janakiwh@gmail.com

Received: July 2017

Accepted: August 2017 